\title{
Neutralization of IL-17 ameliorates uveitis but damages photoreceptors in a murine model of spondyloarthritis
}

\author{
Jelena M Kezic ${ }^{1,2}$, Tibor T Glant ${ }^{3}$, James T Rosenbaum ${ }^{1,4,5^{*}}$ and Holly L Rosenzweig ${ }^{1,6}$
}

\begin{abstract}
Introduction: Uveitis, or intraocular inflammatory disease, is a frequent extra-articular manifestation of several forms of arthritis. Despite the frequent co-occurrence of uveitis and arthritis, little is understood of the eye's predisposition to this disease. We recently described a previously unreported uveitis in a murine model of spondyloarthropathy triggered by autoimmunity to aggrecan, a prominent proteoglycan (PG) macromolecule in cartilage. In contrast to the joint and spine, wherein interferon-gamma (IFNy) deficiency reduced disease, IFN $\gamma$ deficiency worsened uveitis. Given the regulatory role of IFN $\gamma$ on the Th17 response and the current focus of antiinterleukin-17 therapeutics in patients with uveitis and spondyloarthritis, we sought to determine the extent to which interleukin (IL)-17 mediates uveitis in the absence of IFN $\gamma$.
\end{abstract}

Methods: Antigen specific T cell cytokine production was measured in splenocyte cultures using multiplex-ELISA. Transgenic (Tg) mice expressing the T cell receptor (TCR) recognizing the dominant arthritogenic epitope in the G1 domain of PG (TCR-Tg), also lacking IFN $\gamma$, were immunized with PG. Mice were then systemically administered an anti-IL-17 neutralizing antibody. The onset and severity of peripheral arthritis was evaluated by clinical scoring criteria and histology. Uveitis was assessed using intravital videomicroscopy, which visualizes leukocyte trafficking within the vasculature and tissue of the iris, and by histology.

Results: TCR-Tg splenocytes stimulated in vitro with recombinant G1 peptide demonstrated exacerbated production of cytokines, such as macrophage inflammatory protein (MIP)-1 $\alpha$, MIP- $1 \beta$, IL-1 $\beta$, and most notably IL17A as a consequence of IFN $\gamma$ deficiency. In vivo, IL-17 inhibition prevented the component of PG-induced arthritis that occurs independently of IFN $\gamma$. Blockade of IL-17 ameliorated the ongoing leukocyte trafficking responses within the iris vasculature and tissue, which coincided with reduced infiltration of leukocytes within the anterior and posterior eye segments. However, the anti-IL-17 treatment resulted in unanticipated photoreceptor toxicity.

Conclusions: These data support a protective, regulatory role for IFN $\gamma$ in suppression of IL-17-mediated intraocular disease and to a lesser extent, joint disease. The unanticipated photoreceptor toxicity raises some caution regarding the use of anti-IL-17 therapeutics until the mechanism of this potential effect is determined.

\section{Introduction}

Uveitis, or intraocular inflammatory disease, is a leading cause of visual loss and the most common, clinically important extra-articular manifestation in several several diseases such as ankylosing spondylitis (AS), Behçet's disease, and juvenile idiopathic arthritis. Anterior uveitis, wherein the iris tissue is consistently affected, is the

\footnotetext{
* Correspondence: rosenbaj@ohsu.edu

'Casey Eye Institute, Oregon Health \& Science University, 3181 SW Sam

Jackson Park Rd., Portland, OR 97239, USA

Full list of author information is available at the end of the article
}

most frequently diagnosed type of uveitis in North America and Europe and occurs in as many as $50 \%$ of patients with AS [1,2]. Despite the high incidence of uveitis with AS and its closely related spondyloarthropathies [3], the mechanism for their coexistence is not known. Indeed, uveitis has not been a reported feature in mouse models of arthritic disease.

We recently discovered that uveitis develops in a murine model of spondyloarthropathy that arises from autoimmunity to the cartilage proteoglycan (PG) aggrecan [4], which is a proposed potential autoantigen in AS [5].

\section{C) Biomed Central}


Experimental PG-induced uveitis appears to replicate to some extent the spectrum of human uveitis that occurs in patients with spondyloarthritis. In this mouse model, disease is induced by immunization of genetically susceptible BALB/c mice with PG or its G1 domain [6]. A progressive and chronic erosive polyarthritis and axial spondylitis ensue [7-9]. PG-arthritis is a T cell-dependent disease [10] in which the Th1 effector response plays an important pathogenic role in the peripheral joint disease $[11,12]$. Transgenic (Tg) mice expressing the $\mathrm{T}$ cell receptor (TCR) recognizing an arthritogenic epitope of PG (denoted here as TCR-Tg mice) develop an earlier onset and more severe form of polyarthritis than wild-type mice [13]. We previously reported an unexpected discordant mechanism of disease in the eyes versus joints with respect to interferon-gamma (IFN $\gamma$ ) in TCR-Tg mice. Mice deficient in IFN $\gamma$ develop exacerbated uveitis that is characterized by infiltrating granulocytes, whereas the joint and axial disease are ameliorated by IFN $\gamma$ deficiency [4].

The Th17 signaling axis has emerged as a potential therapeutic target, and anti-IL-17 therapy is currently under evaluation for spondyloarthritis and related diseases, including psoriatic arthritis, psoriasis, inflammatory bowel disease, Behçet's disease and uveitis [14,15]. Given the counter-regulatory role for IFN $\gamma$ on the Th17 responses, the present study was designed to examine whether the exacerbated uveitis that occurs in the absence of IFN $\gamma$ results from an imbalance of the Th17 response. Here, we demonstrate that antigen-specific $\mathrm{T}$ cell production of IL-17A is exacerbated in the absence of IFN $\gamma$. The worsened uveitis that occurs in IFN $\gamma$ KO mice is inhibited by in vivo blockade of IL-17. The remaining arthritis that ensues independently of IFN $\gamma$ is further reduced as a consequence of IL-17 neutralization. However, our findings reveal unanticipated photoreceptor toxicity subsequent to the treatment with antiIL-17 antibody, in that the photoreceptors are frequently obliterated. We conclude that IFN $\gamma$ exerts a critical regulatory role in suppression of IL-17, which is pathogenic in uveitis. Our observations provide insight into a relatively common but poorly understood eye disease and could have potential dual clinical relevance as to how we approach anti-IL-17 therapeutics in patients with uveitis and spondyloarthritis.

\section{Materials and methods}

Mice, immunizations and treatment with anti-IL-17 antibody

TCR-Tg mice [13] that were backcrossed 10 generations onto a BALB/c background were inter-crossed with IFN $\gamma$ KO mice on BALB/c background (The Jackson Laboratory, Bar Harbor, ME, USA); hereon abbreviated GKO/TCR-Tg mice. Housing and experimentation on mice was carried out under approval of the Oregon Health and Science University Animal Care and Use Guidelines. Female, 16-week-old mice were immunized intraperitoneally (i.p.) with $100 \mu \mathrm{g}$ purified human cartilage PG in $200 \mu \mathrm{l}$ phosphate-buffered saline (PBS, pH 7.4) emulsified with dimethyl dioctadecyl ammonium bromide (DDA; Sigma-Aldrich, St. Louis, MO, USA)), along with $1.5 \mu \mathrm{g}$ pertussis toxin (Sigma). Mice received an additional i.p. injection of pertussis toxin $48 \mathrm{~h}$ later, as previously described $[4,16]$. Control groups received PBS/DDA and pertussis toxin injections without PG antigen. For neutralization of IL-17, mice were administered an i.p. injection of $100 \mu \mathrm{g}$ of anti-IL-17 (anti-IL$17 \mathrm{~A}$ and IL-17A/F heterodimer; monoclonal rat IgG2a, clone \# 50104) blocking antibody or $100 \mu$ g of rat IgG2a (isotype control antibody, IC; R\&D Systems, Minneapolis, MN, USA)) at the time of PG-immunization and weekly thereafter. Mice were assessed weekly for clinical manifestations of peripheral arthritis in a masked fashion using an established scoring method as previously described $[4,16]$. The scores ranged from 0 to 4 per paw based on swelling, redness, deformities and ankylosis. The data are represented as the cumulative score for all four paws, resulting in a maximum of 16 per mouse.

\section{Intravital videomicroscopy}

Intraocular inflammation of the iris vasculature and tissue in mice anesthetized with $1.7 \%$ isoflurane was video recorded as previously described $[4,17,18]$. Digital videos (10 sec each) of three independent regions of the iris were captured with a black and white video camera (Kappa Scientific, Gleichen, Germany) on an epifluorescence intravital microscope (modified Orthoplan; Leica, Wetzlar, Germany). Diameter and length of each vessel segment or iris tissue as well as leukocyte phenotype (that is, rolling, adhering, infiltrating) were quantified off-line using Image J analysis software available from NIH.

\section{Histopathology and uveitis scoring}

Eyes and decalcified knee joints were fixed and prepared for paraffin embedding, and $7 \mu \mathrm{m}$ tissue sections were stained with hematoxylin and eosin (H\&E) as previously reported $[19,20]$. For uveitis assessment, eyes were sectioned through the pupillary-optic nerve axis at four different depths and three sections from each depth were examined by a masked observer. Leukocyte infiltration into the aqueous humor of the anterior segment and vitreous body of the posterior segment was quantified as the mean number of cells per section per eye. Structural, morphological and photoreceptor changes to the retina were also assessed using an ocular histopathology grading system, which is indicated as the "structural score" [4]. Both eyes in each mouse were assessed. 


\section{Antigen-specific in vitro splenocyte stimulation}

Splenocytes collected from three individual TCR-Tg or GKO/TCR-Tg mice were plated $\left(2 \times 10^{6}\right.$ cells $\left./ \mathrm{ml}\right)$ in 96-well plates (BD Biosciences, San Diego, CA, USA) as described [21], and cells were stimulated in quadruplicate wells with $20 \mu \mathrm{g} / \mathrm{ml}$ of purified recombinant human (rhG1) domain of aggrecan. Cytokines were measured in supernatants $48 \mathrm{~h}$ post stimulation with Luminex multiplex ELISA (Millipore, Bedford, MA, USA). Data were analyzed using BeadView Multiplex Analysis Software (version 1.0, Upstate Cell Signaling Solutions, Lake Placid, NY, USA)).

\section{Statistical analysis}

Data are represented as mean \pm SEM. Experiments were reproduced at least twice. Means were compared and statistical differences were determined with two-way and one-way analysis of variance (ANOVA) with two-tailed, Students $t$-test post hoc analyses. For the nonparametric clinical arthritis scores and ocular histopathology scores, the Mann-Whitney U test was used (Prism; Graph Pad Software, La Jolla, CA, USA). Probability values $<0.05$ were considered statistically significant.

\section{Results}

IFN $\gamma$ is an essential protective factor against uveitis triggered by proteoglycan autoimmunity

As previously described [4], TCR-Tg mice lacking IFN $\gamma$ (hereon abbreviated GKO/TCR-Tg) develop exacerbated uveitis, which is characterized by increased intravascular cell trafficking responses within the iris, increased glial activation and infiltration of granulocytes. We initially examined the effects of IFN $\gamma$ deficiency on cytokine production in vitro in response to $\mathrm{T}$ cell stimulation with the arthritogenic G1 peptide of PG (Figure 1). Enhanced production of cytokines, such as the Th2-related eosinophilic cytokine, IL-5, as well as higher production of neutrophil chemokines (macrophage inflammatory protein (MIP)- $1 \alpha$ and MIP$1 \beta$ ) occurred as a consequence of IF $\mathrm{\gamma} \gamma$-deficiency. This observation is consistent with the histopathology and predominance of neutrophils and eosinophils observed in uveitic eyes as previously reported in mice lacking IFN $\gamma$ [4]. IL-1 $\beta$ and most notably IL-17A production were markedly enhanced, suggestive of a heightened Th17 response in the absence of IFN $\gamma$. Negligible amounts of IL-23p40 or IL-23p19 were detected (data not shown). The normally abundant IFN $\gamma$ production (plotted on a separate axis, right panel) was abolished in GKO/TCR-Tg mice as expected. These data indicate that in the absence of endogenous IFN $\gamma$, IL-17 production is enhanced that could in turn mediate uveitis.

\section{PG-induced uveitis is dependent on IL-17 in the absence of IFN $\gamma$}

Given the emerging data supporting a key role for IL-17 in patients with AS and related spondyloarthropathies $[22,23]$, we tested whether systemically administered blocking antibody to IL-17 would alter the onset and/or severity of uveitis occurring in the absence of IFN $\gamma$. Using intravital videomicroscopy, a technique that

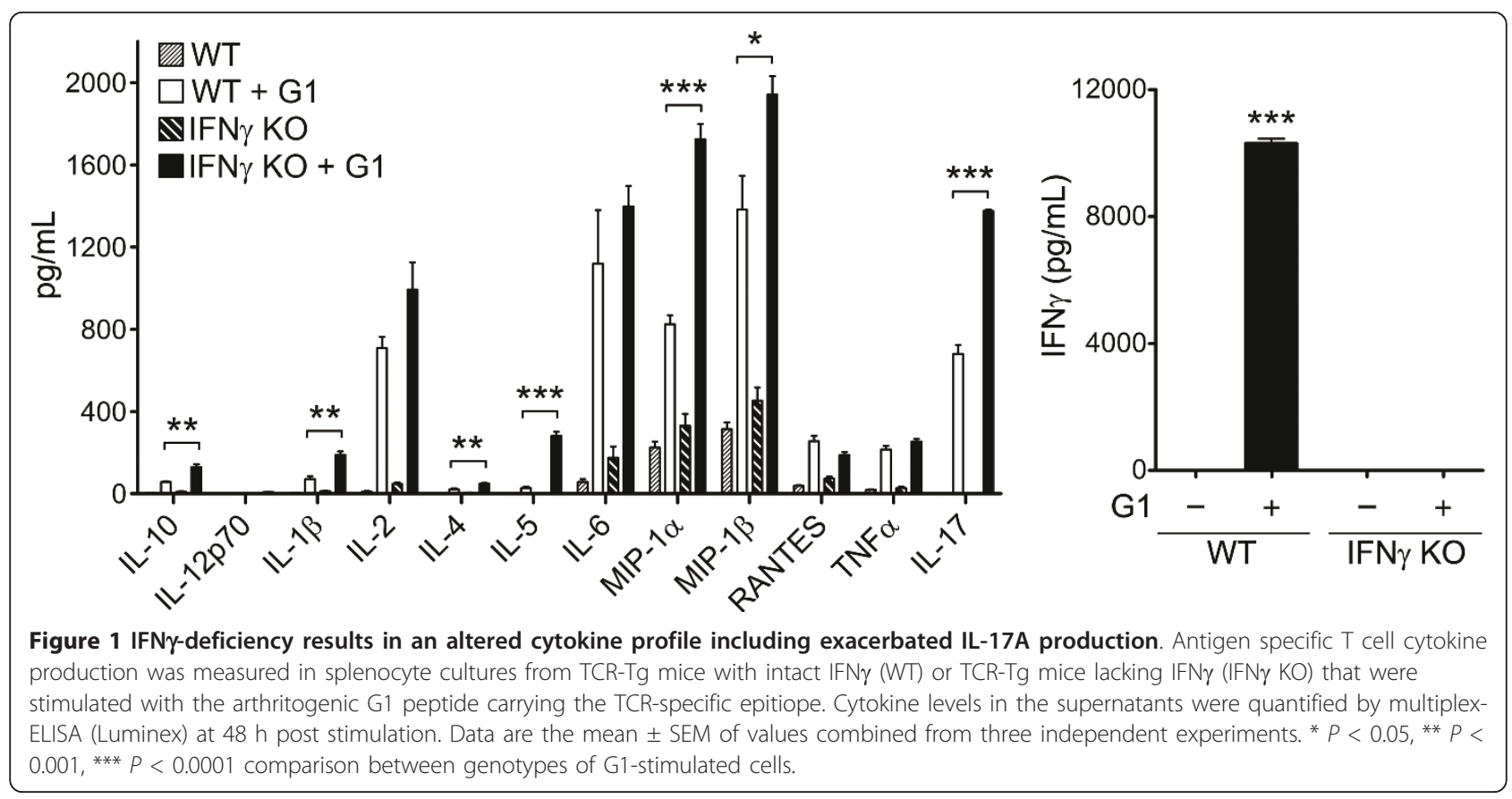


allows us to visualize ongoing cellular trafficking responses in vivo within the iris vasculature and tissue, we examined ocular inflammation at three weeks post immunization, which is a time previously established to consistently coincide with uveitis in this model [4]. As expected, mice that were immunized with adjuvant alone showed negligible ocular inflammation regardless of the antibody treatment (Figure 2A). In contrast, PG immunization of mice treated with the isotype-matched control antibody (IC) resulted in increased leukocyte rolling and adherence within the microvasculature of the iris (Figure 2A) and subsequent infiltration within the iris tissue itself (as depicted in images captured by intravital microscopy (Figure 2B). Neutralization of IL17 in the PG-immunized mice had a profound impact on the cellular trafficking response, as all cellular responses (rolling, adherence and infiltration) in the iris were abolished.

Histopathological examination revealed a near-complete absence of inflammation in both the anterior and posterior eye segments as a consequence of anti-IL-17 therapy (Figure 3). In PG-immunized mice treated with the isotype control antibody an increased presence of infiltrated leukocytes within the aqueous humor, iris, ciliary body, choroid and vitreous body is visualized (as depicted in representative images Figure 3A). Consistent with our prior report, retinal damage such as folding of the inner nuclear layer (INL) and outer nuclear layer (ONL) layers is also a pathological feature of uveitis in mice lacking IFN $\gamma$ (Figure 3A), which is graded using a structural scoring system [4]. In contrast, blockade of IL-17 significantly diminished the number of cells in the aqueous humor of the anterior segment as well as the cells in the vitreous body of the posterior segment (Figure 3A, B). Likewise, IL-17 blockade abolished the retinal vasculitis and retinal folding found in several IFN $\gamma$ deficient mice with PG-induced uveitis (Figure 3C). Despite the abolishment of inflammatory changes in the posterior segment upon IL-17 inhibition, a near-complete ablation of the ONL and photoreceptor layer (PRL) was observed in 9 of the 16 eyes examined (indicated by brackets in Figure 3A). This damage would be expected to result in complete vision loss. As indicated by the brackets, there is a space where the ONL and photoreceptor layers would normally be present, but which are instead missing in PG-immunized mice treated with anti-IL-17A antibody. The depletion in these layers could be a consequence of prior toxicity or cellular death, which may be attributed to these mice having a higher disease structural score then most of the mice

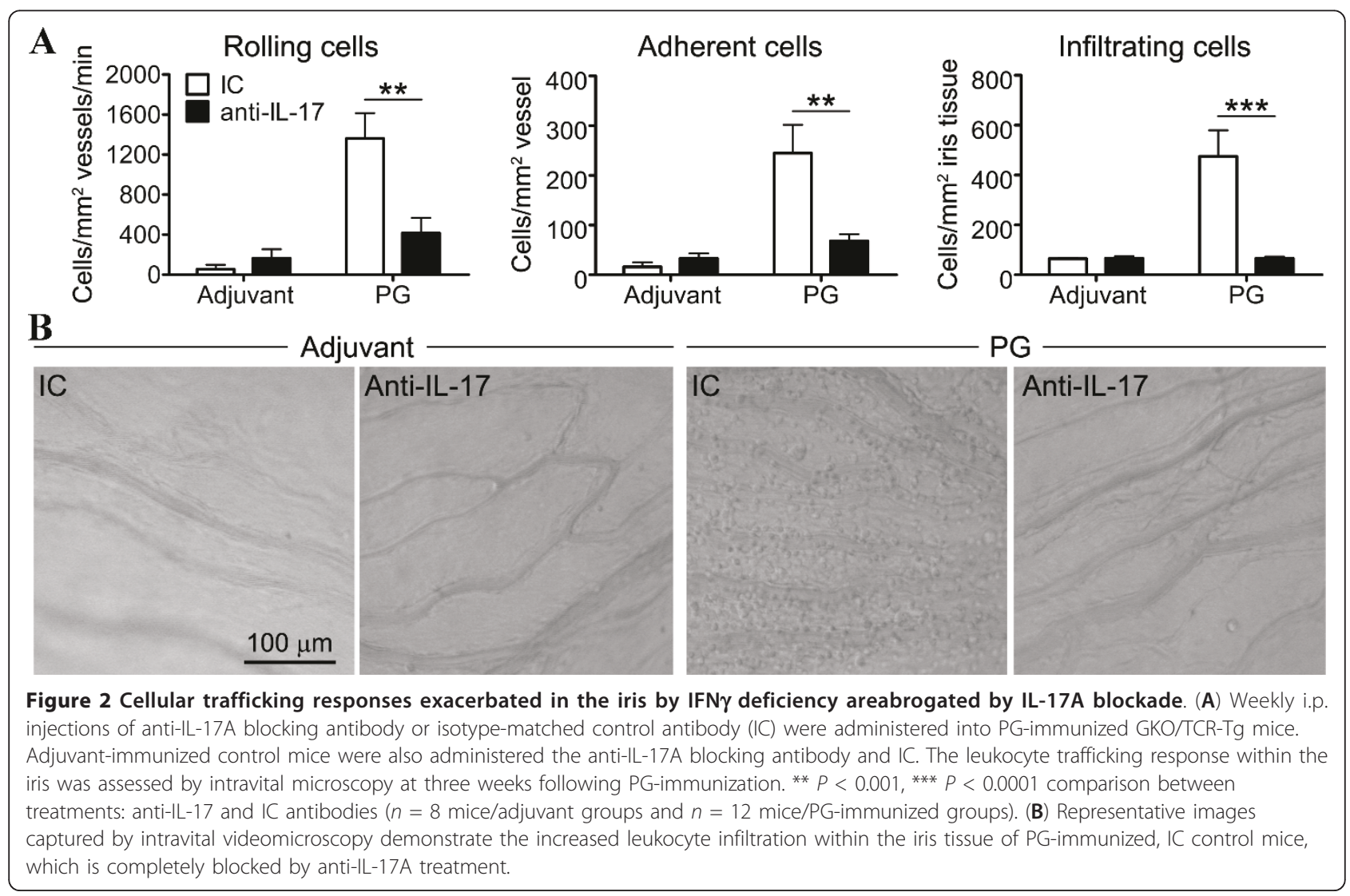




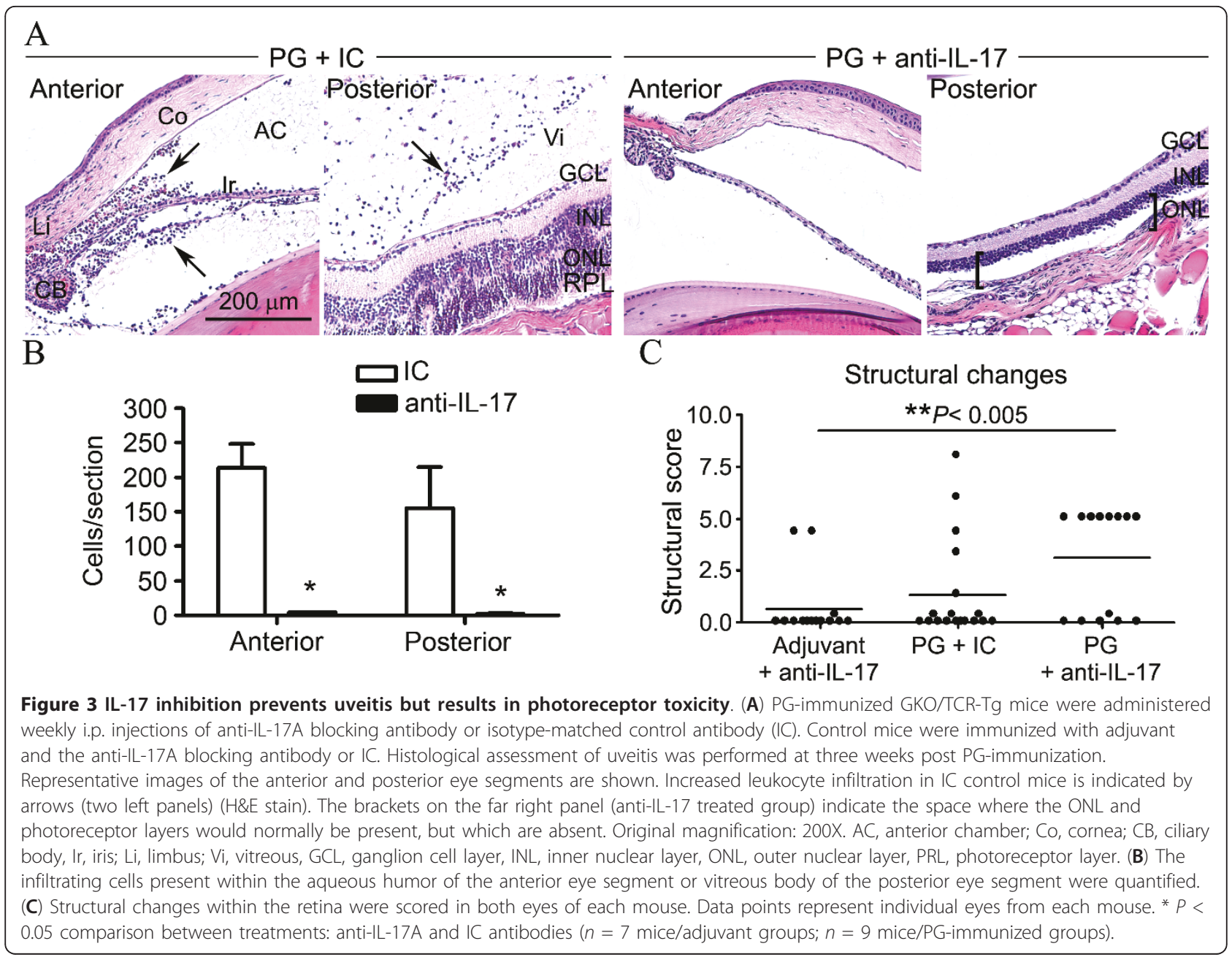

that had received isotype-matched control antibody (Figure $3 \mathrm{C}$ ). We also observed two eyes with similar retinal toxicity in adjuvant-immunized mice that were treated with anti-IL-17 antibody as indicated in the clinical scores for structural changes (Figure 3C). These data support a pathogenic role for IL-17 in uveitis; but PGinduced inflammation also increases the susceptibility of the eyes to the anti-IL-17-induced retinal toxicity.

\section{IL-17 mediates arthritis in the absence of IFN $\gamma$}

PG-induced peripheral arthritis is considered to be primarily a Th1 dependent disease that occurs independently of IL-17 $[11,24,25]$. We have confirmed the pathogenic role for IFN $\gamma$ in promoting peripheral arthritis as well as axial disease in the TCR-Tg mice [4]. However, there is a precedent for IFN $\gamma$ regulating the dependency of IL-17 in arthritis [26], and we demonstrate here that the arthritis ensuing in the absence of IFN $\gamma$ in TCR-Tg mice is mediated by IL-17. PG-induced arthritis that was already attenuated by the absence of IFN $\gamma$ was effectively prevented by anti-IL-17 (Figure
4A). The protective effects of IL-17 blockade observed clinically were corroborated by histological changes (Figure $4 \mathrm{~B}$ ), wherein the synovial inflammation and infiltrated leukocytes were reduced. These data support a combinatorial role for Th1 and Th17 responses in promoting arthritis while IFN $\gamma$ suppresses uveitis through an IL-17-dependent mechanism.

\section{Discussion}

Our prior data demonstrated an important protective role for IFN $\gamma$ in uveitis in a murine model of progressive spondyloarthritis. Here, we tested the extent to which IL-17 mediates uveitis occurring in the absence of IFN $\gamma$. Antigen-specific $\mathrm{T}$ cell production of IL-17A was exacerbated in vitro as a consequence of IFN $\gamma$ deficiency. Assessment of leukocyte trafficking within the iris microvasculature and tissue by intravital videomicroscopy in mice treated with anti-IL-17 neutralizating antibody revealed impaired intravascular responses, such as rolling and adherence that coincided with fewer infiltrating cells in the iris tissue. The histopathology 


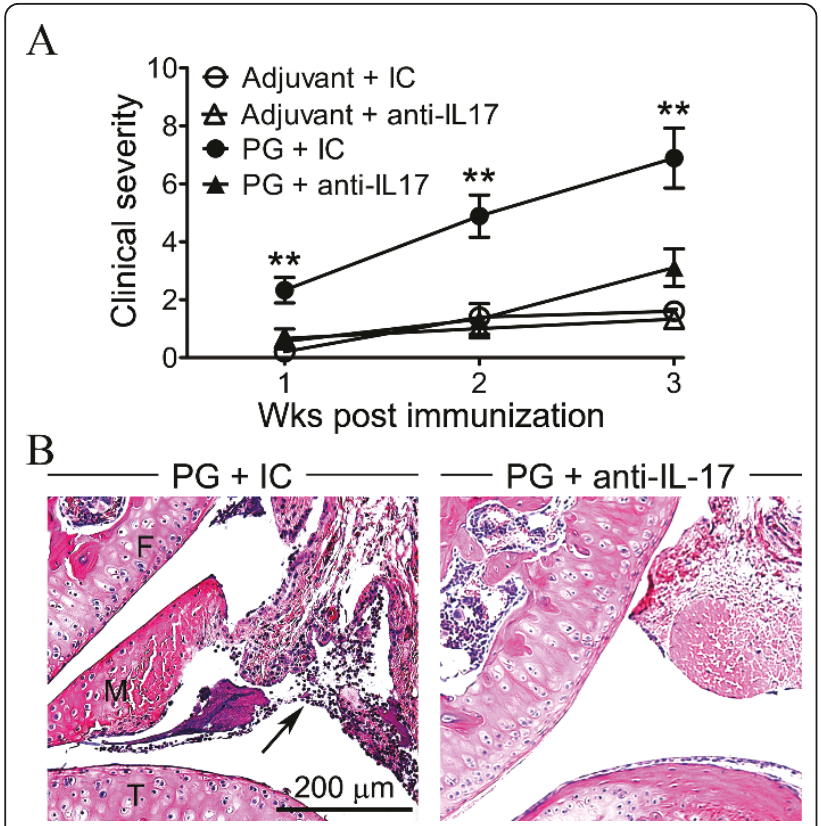

Figure 4 IFN $\gamma$ regulates the requirement for IL-17 in PGinduced arthritis. PG-immunized GKO/TCR-Tg mice were administered weekly i.p. injections of anti-IL-17A blocking antibody or isotype-matched control antibody (IC). Mice were also immunized with adjuvant along with anti-IL-17A blocking antibody and IC. The peripheral arthritis was assessed as a function of time. (A) Clinical arthritic scores in GKO/TCR-Tg mice treated with anti-IL17A or $I C ;{ }^{* *} P<0.001$ comparison between anti-IL-17A and IC antibody treatments in PG-immunized mice ( $n=8$ mice/adjuvant groups and $n=12$ mice/PG-immunized groups). (B) Representative histological images of arthritic knee joints of GKO/TCR-Tg mice treated with IC or anti-IL-17 at three weeks post immunization (F, femur; T, tibia).

demonstrated that IL-17 blockade significantly reduced the number of infiltrating leukocytes within the aqueous humor and vitreous body. The peripheral arthritis that accompanies PG-induced uveitis was also diminished in mice that received the anti-IL-17 blocking antibody. However, despite protective effects of IL-17 inhibition on PG-induced uveitis, unexpected retinal toxicity was observed. Collectively, our data support an important role for IL-17 in the pathogenesis of PG-induced uveitis, which is negatively regulated by IFN $\gamma$.

Uveitis encompasses a heterogeneous group of diseases, and even though it can arise from microbial or viral infection, it is frequently diagnosed in inflammatory diseases involving the joints, such as ankylosing spondylitis, juvenile idiopathic arthritis, Behçet's disease and many others. The underlying mechanisms that result in the co-existence of uveitis and arthritis/spondylitis are poorly understood. An important association exists between HLA-B27 and anterior uveitis in patients with ankylosing spondylitis. Approximately $90 \%$ of affected individuals have the inherited B27 allele [27], but HLA-
B27 does not account for all of the genetic risk for disease, nor the extent to which it influences the onset and severity of uveitis versus spondyloarthritis. For example, HLA-B27 transgenic rats spontaneously develop spondyloarthropathy but do not develop uveitis $[28,29]$. This underscores the complexity of multisystem, immunemediated polygenic diseases, in which environmental factors and/or endogenous microflora can contribute to the pathogenesis of disease within the different target organs.

Although it is not known whether the pathogenic mechanisms in uveitis are the same as arthritis and/or spondylitis, we initially hypothesized that the underlying basic mechanisms would be shared between these two organs in mice immunized with PG. Somewhat paradoxically, however, we found that IFN $\gamma$ deficiency reduced disease in the joint and spine but worsened disease in the eye [4]. The discordant effects of IFN $\gamma$ underscore the complexity of how immune-mediated diseases target multiple organs differentially. This phenomenon has presented considerable challenges in the treatment of uveitis in patients with multisystem diseases, such as Behçet's disease or AS. For example, the TNF $\alpha$ inhibitor, etanercept, diminishes arthritic symptoms in a subgroup of patients with AS [30,31], but it does not always have comparable beneficial effects for uveitis in the same patients [32]; or it can even lead to increased severity of uveitis [33]. Understanding the unique aspects of individually affected tissues is clearly pertinent to the design of optimal therapies.

The data presented here suggest that IFN $\gamma$ is protective in the eye by virtue of being counter-regulatory to the IL-17 response. Studies with various KO mice or blocking antibodies have dissected the separate roles of Th1 and Th17 effector responses in the peripheral arthritis aspect of the PG-induced disease model $[11,24,25]$, wherein IFN $\gamma$ serves an an important regulatory role in arthritis [26]. These studies indicate a dominant pathogenic role for IFN $\gamma$ and the Th1 effector response over that of the Th17 response in arthritis. We recently demonstrated a similar pathogenic role for IFN $\gamma$ in peripheral arthritis and extended its contribution to the axial disease that develops in TCR-Tg mice [4]. Our findings would indicated that although the Th17 response is not considered critical in the development of PG-induced joint disease, it does appear to be a prevailing response contributing to uveitis.

Th17 cells have been reported to play a role in induction of the animal model of posterior uveitis, experimental autoimmune uveitis (EAU) [34] and have been implicated in uveitis clinically $[35,36]$. IL-17 is thought to contribute to disease through its ability to promote recruitment and activation of neutrophils, which is consistent with our previously reported increase in 
granulocyte numbers in PG-immunized mice lacking IFN $\gamma$ [4]. The production of IL-17 from T cells is welldescribed, yet additional cellular sources including $\gamma \delta \mathrm{T}$ cells, NKT cells, macrophages, mast cells and neutrophils may be just as important as the T cells [37-40]. Indeed, a recent report supports the role of innate immune cells rather than T cells in expression of IL-17 in the joints of patients with spondyloarthritis [41]. Thus, the pathology of uveitis observed in response to PG-immunization could involve coordinated events between the T cells of the Th1 and Th17 lineages and innate immune cells, which then propagate tissue damage within uveitic eyes. Future studies that compare the cytokine sources along with their targets within uveitic eyes versus the arthritic joints will be informative.

The IL-23/IL-17 axis is a major focus of spondyloarthritis research, and many pharmaceutical companies are actively working on strategies to block IL-17 in uveitis, AS and related spondyloarthropathies $[14,15,36,42]$. Therefore, it is critical to understand how this cytokine can contribute to immune-mediated uveitis models in mice, and possibly in humans. Although reduced clinical signs of arthritis and ocular disease following anti-IL-17 treatment suggest great therapeutic potential for the use of this antibody, our observations of retinal toxicity indicate the need to proceed cautiously. We were unable to measure visual acuity, however the observed depletion of photoreceptors and ONL would be expected to result in near to complete vision loss. This observation brings to question why inhibition of IL-17 may result in toxicity within the eye. We are not aware of any reports that demonstrate a role or involvement of IL-17A in the survival of retinal cells. Nonetheless, a number of studies implicate IL-17A involvement in apoptotic or cell survival responses in different cell types and diseases [43-45], suggesting its potential role in cellular viability within the eye. Retinal toxicity derived from anti-IL-17 antibody treatments has not been previously reported in other murine uveitis models $[34,46,47]$, indicating that the toxicity could possibly involve a combination of events within this particular disease model, such as glial cell activation within the retina, the presence of PGantigen within the retina, and/or ongoing systemic disease [4]. At the time examined here (three weeks post PG-immunization), the photoreceptor toxicity did not coincide with increased expression of GFAP (glial fibrillary acidic protein, a marker of glial activation, data not shown). However, we cannot rule out the contribution of glial activation at times preceding photoreceptor toxicity. Studies are underway to elucidate whether inhibiting the Th17 response through targeting IL-17R or the upstream cytokine IL-23 reduces uveitis without photoreceptor damage. These studies would inform us to the potential toxicity effects of this particular antibody versus the contribution of the Th17 pathway in photoreceptor viability. The observations presented here yield valuable information regarding contrasting mechanisms of disease within different portions of the body and could have an impact on how we approach therapy in complex, inflammatory diseases.

\section{Conclusions}

The present study demonstrates an important regulatory role for IFN $\gamma$ in uveitis associated with a murine model of spondyloarthropathy. Antigen-specific activation of naive TCR-Tg T cells lacking IFN $\gamma$ in culture resulted in enhanced cytokine levels of IL-17A, which correlated with worsened uveitis but not arthritis in PG-immunized mice. Blockade of IL-17 in vivo ameliorated the ongoing cell trafficking responses within the iris vasculature and iris tissue, which coincided with diminished leukocyte accumulation within the aqueous humor and vitreous body. The residual arthritis ensuing in the absence of IFN $\gamma$ was further reduced by anti-IL-17 neutralization. These data support a combinatorial role for Th1 and Th17 responses in arthritis, which is in opposition to the eye wherein we discovered a counter-regulatory role for Th1 and Th17 responses in uveitis. Despite the beneficial anti-inflammatory effects of the anti-IL-17 blocking antibody, caution must be exercised in developing anti-IL-17 therapeutics for uveitis due to the unexpected photoreceptor toxicity. Investigation of simultaneous eye and joint disease within a mouse could reveal important insights into how we approach therapy in uveitic patients with inflammatory diseases such as AS.

\section{Abbreviations}

AC: anterior chamber; AS: ankylosing spondylitis; CB: ciliary body; Co: cornea; DDA: dimethyl dioctadecyl ammonium bromide; F: femur; GCL: ganglion cell layer; GKO/TCR-Tg mice: TCR-Tg mice deficient in IFNY; IC: isotype control antibody; INL: inner nuclear layer; i.p.: intraperitoneal; Ir: iris; Li: limbus; ONL: outer nuclear layer; PG: the proteoglycan aggrecan; PRL: photoreceptor layer; T: tibia; TCR-Tg mice: transgenic mice expressing the TCR for the arthritogenic epitope of PG; Vi: vitreous; WT: wild-type.

\section{Acknowledgements}

The authors are grateful to Jenna S. Clowers, Katie Dahlhausen and Stephanie Tarlow for their technical support along with Drs. Stephen R. Planck and Michael P. Davey for their critical discussions and review of the manuscript. This work was supported by NIH (NEI grants EY019020, EY010572 and EY019604). HLR also receives support from the American College of Rheumatology Research and Education Foundation Health Professional New Investigator Award and Research to Prevent Blindness Foundation. The authors would also like to thank the William C. Kuzell Foundation, the Stan and Madelle Rosenfeld Family Trust, and the William and Mary Bauman Foundation for their support.

\section{Author details}

${ }^{1}$ Casey Eye Institute, Oregon Health \& Science University, 3181 SW Sam Jackson Park Rd., Portland, OR 97239, USA. ${ }^{2}$ JMK is now affiliated with Centre for Eye Research Australia, University of Melbourne, East Melbourne VIC, 3002 
Australia; and Department of Anatomy and Developmental Biology, Monash University, Melbourne, VIC, Australia. ${ }^{3}$ Departments of Biochemistry and Orthopedics, Rush University Medical Center, 1735 W. Harrison St., Chicago, IL 60612, USA. ${ }^{4}$ Department of Medicine, Oregon Health \& Science University, 3181 SW Sam Jackson Park Rd., Portland, OR 97239, USA. ${ }^{5}$ Department of Cell and Developmental Biology, Oregon Health \& Science University, 3181 SW Sam Jackson Park Rd., Portland, OR 97239, USA. ${ }^{6}$ Department of Molecular Microbiology and Immunology, Oregon Health \& Science University, 3181 SW Sam Jackson Park Rd., Portland, OR 97239, USA.

\section{Authors' contributions}

JK carried out the experiments, participated in acquisition of the data, analysis and interpretation of the data, and the manuscript preparation. TG participated in the acquisition of in vitro data through provision of recombinant G1 domain, interpretation of data and helped to draft the manuscript. JR participated in the design of the study, interpretation of data, and manuscript preparation. HR conceived of the study, participated in the design, data analysis, interpretation and manuscript preparation. All authors read and approved the final manuscript.

\section{Competing interests}

The authors declare they have no competing interests except for JTR, who has consulted for Novartis, Amgen, Genentech, Pfizer, Abbott, UBC, Xoma and Allergan.

Received: 25 October 2011 Revised: 12 December 2011 Accepted: 23 January 2012 Published: 23 January 2012

\section{References}

1. Nussenblatt RB: The natural history of uveitis. Int Ophthalmol 1990, 14:303-308.

2. Zeboulon N, Dougados M, Gossec L: Prevalence and characteristics of uveitis in the spondyloarthropathies: a systematic literature review. Ann Rheum Dis 2008, 67:955-959.

3. Braun J, Sieper J: Ankylosing spondylitis. Lancet 2007, 369:1379-1390.

4. Kezic JM, Davey MP, Glant TT, Rosenbaum JT, Rosenzweig HL: IFNy regulates discordant mechanisms of uveitis versus joint and axial disease in a murine model resembling spondyloarthritis. Arthritis Rheum 2011, [Epub ahead of print].

5. Zou J, Appel H, Rudwaleit M, Thiel A, Sieper J: Analysis of the CD8+ T cell response to the G1 domain of aggrecan in ankylosing spondylitis. Ann Rheum Dis 2005, 64:722-729.

6. Glant TT, Radacs M, Nagyeri G, Olasz K, Laszlo A, Boldizsar F, Hegyi A, Finnegan A, Mikecz K: Proteoglycan-induced arthritis and recombinant human proteoglycan aggrecan G1 domain-induced arthritis in BALB/C mice resembling two subtypes of rheumatoid arthritis. Arthritis Rheum 2011, 63:1312-1321.

7. Glant TT, Cs-Szabo G, Nagase H, Jacobs JJ, Mikecz K: Progressive polyarthritis induced in BALB/c mice by aggrecan from normal and osteoarthritic human cartilage. Arthritis Rheum 1998, 41:1007-1018.

8. Glant TT, Finnegan A, Mikecz K: Proteoglycan-induced arthritis: immune regulation, cellular mechanisms, and genetics. Crit Rev Immunol 2003, 23:199-250.

9. Bardos T, Szabo Z, Czipri M, Vermes C, Tunyogi-Csapo M, Urban RM, Mikecz K, Glant TT: A longitudinal study on an autoimmune murine model of ankylosing spondylitis. Ann Rheum Dis 2005, 64:981-987.

10. Buzas El, Brennan FR, Mikecz K, Garzo M, Negroiu G, Hollo K, Cs-Szabo G, Pintye $E$, Glant TT: A proteoglycan (aggrecan)-specific T cell hybridoma induces arthritis in BALB/c mice. J Immunol 1995, 155:2679-2687.

11. Cao Y, Doodes PD, Glant TT, Finnegan A: IL-27 induces a Th1 immune response and susceptibility to experimental arthritis. J Immunol 2008, 180:922-930.

12. Finnegan A, Grusby MJ, Kaplan CD, O'Neill SK, Eibel H, Koreny T, Czipri M, Mikecz K, Zhang J: IL-4 and IL-12 regulate proteoglycan-induced arthritis through Stat-dependent mechanisms. J Immunol 2002, 169:3345-3352.

13. Berlo SE, Guichelaar T, Ten Brink CB, van Kooten PJ, Hauet-Broeren F, Ludanyi $K$, van Eden W, Broeren CP, Glant TT: Increased arthritis susceptibility in cartilage proteoglycan-specific T cell receptor-transgenic mice. Arthritis Rheum 2006, 54:2423-2433.

14. Yeremenko N, Baeten D: IL-17 in spondyloarthritis: is the T-party over? Arthritis Rheum 2011, 13:115.
15. Song $\mathbb{H}$, Poddubnyy D: New treatment targets in ankylosing spondylitis and other spondyloarthritides. Curr Opin Rheumatol 2011, 23:346-351.

16. Glant TT, Mikecz K: Proteoglycan aggrecan-induced arthritis: a murine autoimmune model of rheumatoid arthritis. Methods Mol Med 2004, 102:313-338.

17. Rosenzweig HL, Martin TM, Jann MM, Planck SR, Davey MP, Kobayashi K, Flavell RA, Rosenbaum JT: NOD2, the gene responsible for familial granulomatous uveitis, is essential in a mouse model of muramyl dipeptide-induced uveitis. Invest Ophthalmol Vis Sci 2008, 49:1518-1524.

18. Becker MD, Nobiling R, Planck SR, Rosenbaum JT: Digital video-imaging of leukocyte migration in the iris: intravital microscopy in a physiological model during the onset of endotoxin-induced uveitis. I Immunol Methods 2000, 240:23-37.

19. Rosenzweig HL, Jann MJ, Vance EE, Planck SR, Rosenbaum JT, Davey MP: Nucleotide-binding oligomerization domain 2 and Toll-like receptor 2 function independently in a murine model of arthritis triggered by intraarticular peptidoglycan. Arthritis Rheum 2010, 62:1051-1059.

20. Rosenzweig H, Galster K, Planck S, Rosenbaum JT: NOD1 expression in the eye and functional contribution to IL-1\{beta\} dependent ocular inflammation in mice. Invest Ophthalmol Vis Sci 2009, 50:1746-1753.

21. Rosenzweig HL, Jann MM, Glant T, Martin TM, Planck SR, Van Eden W, Van Kooten PJ, Flavell RA, Kobayashi K, Rosenbaum JT, Davey MP: Activation of nucleotide oligomerization domain 2 exacerbates a murine model of proteoglycan-induced arthritis. J Leukoc Biol 2009, 85:711-718.

22. Wendling D, Cedoz JP, Racadot E, Dumoulin G: Serum IL-17, BMP-7, and bone turnover markers in patients with ankylosing spondylitis. Joint Bone Spine 2007, 74:304-305.

23. Wang X, Lin Z, Wei Q, Jiang Y, Gu J: Expression of IL-23 and IL-17 and effect of IL-23 on IL-17 production in ankylosing spondylitis. Rheumatol Int 2009, 29:1343-1347.

24. Finnegan A, Mikecz K, Tao P, Glant TT: Proteoglycan (aggrecan)-induced arthritis in BALB/c mice is a Th1-type disease regulated by Th2 cytokines. J Immunol 1999, 163:5383-5390.

25. Doodes PD, Cao Y, Hamel KM, Wang Y, Farkas B, Iwakura Y, Finnegan A: Development of proteoglycan-induced arthritis is independent of IL-17. J Immunol 2008, 181:329-337.

26. Doodes PD, Cao Y, Hamel KM, Wang Y, Rodeghero RL, Mikecz K, Glant TT, Iwakura Y, Finnegan A: IFN-gamma regulates the requirement for IL-17 in proteoglycan-induced arthritis. J Immunol 2010, 184:1552-1559.

27. Feltkamp TEW: HLA B27, acute anterior uveitis, and ankylosing spondylitis. Adv Inflamm Res 1985, 9:211-216.

28. Hammer RE, Maika SD, Richardson JA, Tang JP, Taurog JD: Spontaneous inflammatory disease in transgenic rats expressing HLA-B27 and human beta $2 \mathrm{~m}$ : an animal model of HLA-B27-associated human disorders. Cell 1990, 63:1099-1112.

29. Baggia S, Lyons J, Angell E, Barkhhizen A, Han YB, Planck SR, Taurog JD, Rosenbaum JT: A novel model of bacterially-induced acute anterior uveitis in rats and the lack of effect from HLA B27 expression. J Investig Med 1997, 45:295-301.

30. Zochling J, Van der Heijde D, Burgos-Vargas R, Collantes E, Davis JC Jr, Dijkmans B, Dougados M, Geher P, Inman RD, Khan MA, Kvien TK, LeirisaloRepo M, Oliveieri I, Pavelka K, Sieper J, Stucki G, Sturrock RD, van der Linden S, Wendling D, Bohm H, van Royen BJ, Braun J, 'Assessment in AS' international working group, European League Against Rheumatism: ASAS/ EULAR recommendations for the management of ankylosing spondylitis. Ann Rheum Dis 2006, 65:442-452.

31. Sfikakis PP: The first decade of biologic TNF antagonists in clinical practice: lessons learned, unresolved issues and future directions. Curr Dir Autoimmun 2010, 11:180-210.

32. Smith JR, Levinson RD, Holland GN, Jabs DA, Robinson MR, Whitcup SM, Rosenbaum JT: Differential efficacy of tumor necrosis factor inhibition in the management of inflammatory eye disease and associated rheumatic disease. Arthritis Rheum 2001, 45:252-257.

33. Lim LL, Fraunfelder FW, Rosenbaum JT: Do tumor necrosis factor inhibitors cause uveitis? A registry-based study. Arthritis Rheum 2007, 56:3248-3252.

34. Luger D, Silver PB, Tang J, Cua D, Chen Z, Iwakura Y, Bowman EP, Sgambellone NM, Chan CC, Caspi RR: Either a Th17 or a Th1 effector response can drive autoimmunity: conditions of disease induction affect dominant effector category. J Exp Med 2008, 205:799-810. 
35. Amadi-Obi A, Yu CR, Liu X, Mahdi RM, Clarke GL, Nussenblatt RB, Gery I, Lee YS, Egwuagu CE: TH17 cells contribute to uveitis and scleritis and are expanded by IL-2 and inhibited by IL-27/STAT1. Nat Med 2007, 13:711-718.

36. Hueber W, Patel DD, Dryja T, Wright AM, Koroleva I, Bruin G, Antoni C, Draelos Z, Gold MH, Psoriasis Study Group, Durez P, Tak PP, Gomez-Eino JJ, Rheumatoid Arthritis Study Group, Foster CS, Kim RY, Samson CM, Falk NS, Chu DS, Callanan D, Nguyen QD, Uveitis Study Group, Rose K, Haider A, D Padova F: Effects of AIN457, a fully human antibody to interleukin-17A, on psoriasis, rheumatoid arthritis, and uveitis. Sci Transl Med 2010, 2:52ra72.

37. Cua DJ, Tato CM: Innate IL-17-producing cells: the sentinels of the immune system. Nat Rev Immunol 2010, 10:479-489.

38. Gaffen SL: Recent advances in the IL-17 cytokine family. Curr Opin Immunol 2011, 23:1-7.

39. Moran EM, Heydrich R, Ng CT, Saber TP, McCormick J, Sieper J, Appel H, Fearon U, Veale DJ: IL-17A expression is localised to both mononuclear and polymorphonuclear synovial cell infiltrates. PLos One 2011, 6:e24048.

40. Mills KH: Induction, function and regulation of IL-17-producing T cells. Eur J Immunol 2008, 38:2636-2649.

41. Appel H, Maier R, Wu P, Scheer R, Hempfing A, Kayser R, Thiel A, Radbruch A, Loddenkemper C, Sieper J: Analysis of IL-17+ cells in facet joints of patients with spondyloarthritis suggests that the innate immune pathway might be of greater relevance than the Th17mediated adaptive immune response. Arthritis Res Ther 2011, 13:R95.

42. Gottlieb A, Menter A, Mendelsohn A, Shen YK, Li S, Guzzo C, Fretzin S, Kunynetz R, Kavanaugh A: Ustekinumab, a human interleukin 12/23 monoclonal antibody, for psoriatic arthritis: randomised, double-blind, placebo-controlled, crossover trial. Lancet 2009, 373:633-640.

43. Zhu F, Wang Q, Guo C, Wang X, Cao X, Shi Y, Gao F, Ma C, Zhang L: IL-17 induces apoptosis of vascular endothelial cells - a potential mechanism for human acute coronary syndrome. Clin Immunol 2011, 141:152-160.

44. Cunnusamy K, Chen PW, Niederkorn JY: IL-17 promotes immune privilege of corneal allografts. J Immunol 2010, 185:4651-4658.

45. Kirshberg S, Izhar U, Amir G, Demma J, Vernea F, Beider K, Shlomai Z, Wald H, Zamir G, Shapira OM, Peled A, Wald O: Involvement of CCR6/ CCL20/IL-17 axis in NSCLC disease progression. PLOS One 2011, 6:e24856.

46. Zhang Z, Zhong W, Spencer D, Chen H, Lu H, Kawaquchi T, Rosenbaum JT: Interleukin-17 causes neutrophil mediated inflammation in ovalbumininduced uveitis in D011.10 mice. Cytokine 2009, 46:79-91.

47. Jiang G, Ke Y, Sun D, Han G, Kaplan HJ, Shao H: Reactivation of uveitogenic $\mathrm{T}$ cells by retinal astrocytes derived from experimental autoimmune uveitis-prone B10RIII mice. Invest Ophthalmol Vis Sci 2008, 49:282-289.

\section{doi:10.1186/ar3697}

Cite this article as: Kezic et al:: Neutralization of IL-17 ameliorates uveitis but damages photoreceptors in a murine model of spondyloarthritis. Arthritis Research \& Therapy 2012 14:R18.

\section{Submit your next manuscript to BioMed Central and take full advantage of:}

- Convenient online submission

- Thorough peer review

- No space constraints or color figure charges

- Immediate publication on acceptance

- Inclusion in PubMed, CAS, Scopus and Google Scholar

- Research which is freely available for redistribution

Submit your manuscript at www.biomedcentral.com/submit
C Biomed Central 